Samuel Freeman, Rawls, traducción de Adolfo García de la Sienra, México, Fondo de Cultura Económica, 2016, 458 pp. ISBN 978041-530-109-1

El Fondo de Cultura Económica publicó un libro indispensable para estudiar la obra del filósofo estadounidense John Rawls en particular y para el debate sobre la justicia en la filosofía y en las ciencias sociales en general: Rawls, de Samuel Freeman, traducido por el profesor Adolfo García de la Sienra y cuya versión original en inglés data de 2007.

Es un libro que culmina una etapa de trabajo analítico, reconstructivo y pedagógico de Freeman, quien ya había ofrecido entregas previas de gran relevancia. La primera, y todavía la más valorada, es la edición de los Collected Papers de John Rawls (Harvard University Press, 1999). En esta compilación, que aún aguarda una traducción al español (si bien la mayor parte de esos textos ya se encuentran en nuestra lengua), Freeman puso a nuestra disposición los materiales previos (que ahora sabemos fueron preparatorios) a la Teoría de la justicia de 1971, los materiales de tránsito hacia el Liberalismo político de 1993, e incluso los materiales posteriores a esta obra y últimos de la producción del acreditado profesor de Harvard. Para quienes en los años noventa nos embarcamos en el estudio de la obra de John Rawls, y que en esa época de Internet rudimentaria sufrimos para conseguir esos textos discretos y dispersos, el trabajo de Freeman llenó los huecos que irremediablemente se nos quedaban y permitió contrastar, desde una perspectiva más amplia, las interpretaciones que entonces aventuramos. Otra entrega de particular importancia fue la edición de The Cambridge Companion to Rawls (Cambridge University Press, 2003), que reúne análisis de la obra de Rawls escritos por sus principales estudiosos, como T. Nagel, J. Cohen y T. M. Scanlon, y en el que aparece una colaboración del propio Freeman ("Congruence and the Good of Justice”) que presagia ya la interpretación de este Rawls que reseñamos. La otra entrega relevante de Freeman fue la edición de Lectures on the History of Political Philosophy (Cambridge, MA, Belknap, Harvard University Press, 2007), que reproduce las conferencias y notas del curso de Filosofía política moderna que Rawls impartió en Harvard desde 1965 hasta 1995. Esta compilación ofrece un extraordinario acercamiento al modo en que Rawls interpretó a pensadores 
clásicos que van de Hobbes a Marx, pasando por Locke y John Stuart Mill. Si a estos materiales facilitados por Freeman sumamos los otros rescates de obras de Rawls: Justice as Fairnees. A Restatement (Cambridge, MA, Belknap/Harvard University Press, 2001) editado por Erin Kelly; Lectures on the History of Moral Philosophy (Cambridge, MA, Harvard University Press, 2000), editado por Barbara Herman, y la controvertida tesis doctoral A Brief Inquiry into the Meaning of Sin and Faith (Cambridge, MA, Harvard University Press, 2009) editada por T. Nagel, tenemos completo el canon del famoso filósofo fallecido en 2002.

Decir que el Rawls de Freeman es una obra que de manera sistemática y pedagógica nos conduce por el vasto pensamiento de Rawls es decir poco, aunque ello sea cierto. Freeman realiza la tarea de reconstruir el sistema rawlsiano desde su base, que para él es el conjunto de conceptos postulados por Rawls en Teoría de la justicia de 1971, por lo que su acercamiento no concede atención específica a los trabajos preparatorios, que van desde el lejano "Outline of a Decision Procedure for Ethics" (1951) hasta "Distributive Justice” (1967). Freeman dedica la mayor parte de su libro, de la página 59 a la 294, al análisis de los dos principios rawlsianos de la justicia, de la posición original, de las instituciones justas, del problema de la estabilidad y del constructivismo kantiano, todos ellos de Teoría de la justicia. Menos desarrollo dedica a la revisión de Liberalismo político, entre las páginas 295 y 371, donde primero analiza el dominio de lo político - y, en especial, la concepción política de la justicia - y luego los temas del consenso traslapado (overlapping consensus) y la razón pública. Remata el análisis con el estudio de "La ley de los pueblos", entre las páginas 372 y 405, para agregar una breve pero sustanciosa "Conclusión” en la que evalúa el aporte y trascendencia de la obra de Rawls para nuestros días.

Esa es la línea pedagógica del texto y, siendo clara y coherente, constituye una ruta de acceso al estudio de John Rawls de indudable eficacia. Ofrece un sistema rawlsiano aliviado de confusiones y contradicciones, aunque poco sujeto a crítica. Transita, conforme a la cronología de publicación, de la teoría de la justicia como equidad (o imparcialidad) de los primeros años setenta a la concepción rawlsiana de justicia internacional de los noventa. Empero, otra línea de trabajo, más hermenéutica, atraviesa la reconstrucción realizada por Freeman y 
resulta todavía más interesante. Ésta tiene como eje el capítulo V: "La estabilidad de la justicia como imparcialidad” (pp. 127-262). Después de revisarla, podemos sugerir que el libro de Freeman se lea a partir de esta reconstrucción del problema de la estabilidad, pues allí reside su clave de interpretación para la obra rawlsiana en su conjunto.

Cabe señalar que Freeman dedica muchas más páginas al tema de la estabilidad de la justicia como equidad que lo dedicado por el propio Rawls. En efecto, en $A$ Theory of Justice, Rawls dedicó sólo 8 páginas (de la 496 a la 504 en la edición de Oxford University Press de 1973) a la "estabilidad relativa” en una sección de su obra ("Parte III: Fines") que, benévolamente, puede ser adjetivada como miscelánea. De hecho, ningún estudioso relevante de Rawls dedicó mayor atención a este segmento del libro hasta que el propio Rawls sostuvo, en el Liberalismo político (1993), que su libro de 1971 fallaba al encarar el problema de la estabilidad y que ello hacía necesaria la formulación de una teoría del liberalismo político. En 1971, Rawls había sostenido que un arreglo institucional justo es estable cuando el sentido de la justicia desarrollado entre los hombres que lo pueblan es suficientemente poderoso como para vencer las tentaciones de no acatar las reglas comunes. Rawls vincula este sentido de la justicia con propensiones o leyes psicológicas relativas al sentido del valor propio, a la solidaridad y a la negativa al abuso, todas ellas culturalmente construidas, pero todas también vinculadas al contenido moral de la justicia como imparcialidad. En Liberalismo político, Rawls sostuvo que el entendimiento de su propia teoría de la justicia como doctrina única equivalente al bien social introducía el supuesto erróneo de que una doctrina comprehensiva podía ser la base de la estabilidad social, mientras que en realidad una sociedad está marcada, de manera irreductible, por una pluralidad de doctrinas filosóficas, religiosas y morales. De ese modo, si hubiera que buscar la estabilidad de la justicia tendría que hacerse sobre la base de un consenso de las doctrinas (a través de su módulo o núcleo de ideas de la justicia y fundamentos constitucionales) y no a partir de contenidos morales o filosóficos.

Aunque autores como Brian Barry sostuvieron en temprana hora que Rawls aludía a un falso problema, pues la distinción entre lo político y lo doctrinario ya estaba contenida en la prioridad de lo correcto (the Right) sobre lo bueno (the Good), Freeman se toma en serio esta 
autointerpretación y la convierte en su criterio de lectura de toda la obra rawlsiana. Uno de los resultados de esta toma de partido es que Freeman describe a un Rawls claramente antikantiano desde los años setenta, y abiertamente pragmatista y contextualista desde entonces. Nos ofrece, claro está, un Rawls coherente y muy digerible, pero contradice una poderosa imagen intelectual del filósofo de Harvard construida sobre la base de sus supuestos kantismo y universalismo filosóficos. Lo grave es que gran parte del prestigio y atractivo intelectual de Rawls se construyeron precisamente al hilo de esta imagen.

Creo que el magisterio filosófico se articula históricamente conforme a dos tradiciones: llámese a una platónica y a la otra aristotélica. En la primera, como Platón respecto de Sócrates, el discípulo glosa al maestro, preserva su legado y, si es el caso, aclara lo necesario para la mejor proyección del discurso original. En la segunda, como Aristóteles respecto de Platón, el discípulo absorbe las ideas centrales del maestro, las revisa, las impugna - a veces, incluso, se burla un poco- y construye un discurso alternativo. No cabe duda de que el Rawls de Freeman se inscribe en un magisterio platónico. Si bien no estamos ante una hagiografía, sí vemos una muy caritativa lectura de los argumentos de Rawls y una necesidad de encontrar coherencia y sentido donde a veces es dudoso que existan. Ello explicaría que algunas ausencias y déficits de la obra de Rawls lo sean también de Freeman. De manera destacada, el problema de la discriminación racial o de género, que en Justice as Fairness. A Restatement, de 2002, el propio Rawls había calificado como un "olvido" subsanable de su teoría, no merece aquí mayor consideración. Un poco de aristotelismo magisterial no lo hubiera demeritado.

\section{SOBRE LA TRADUCCIÓN}

Una reseña debería dedicar poca, si no nula, atención a la traducción de un libro. Sobre todo cuando, como es el caso, el texto en español es claro, pulcro y fluido. Pero en la tradición de estudios rawlsianos en español, el de la traducción se convierte en un tema obligado enfrentamos un problema rawlsiano que no existe en su original lengua inglesa. Este problema se generó a partir de la publicación de la traducción 
canónica de $A$ Theory of Justice por el Fondo de Cultura Económica en 1979, a cargo de María Dolores González, y titulada Teoría de la justicia. Para no entrar en los numerosos problemas conceptuales y terminológicos que en esa versión fueron identificados por estudios como los de María Xosé Agra y Manuel Jiménez Redondo (“¿Es la versión castellana de $A$ Theory of Justice de John Rawls una versión modificada?”, en Teorema, XIII, 1983, y “A propósito de la versión castellana de la obra de John Rawls A Theory of Justice”, en Teorema, xI, 1981, respectivamente), y siendo el primer problema que lo adecuado hubiera sido denominarla Una teoría de la justicia, baste recordar que el principal desacuerdo es el relativo al modo de verter el término fairness al castellano. La edición del Fondo de Cultura Económica (no hay otra) lo tradujo como "imparcialidad", poniendo a circular el enunciado "justicia como imparcialidad" como la designación en español de la teoría construida por Rawls (justice as fairness). En 1986, se publicaron en Madrid los escritos preparatorios de Rawls para $A$ Theory of Justice, traducidos por Miguel Ángel Rodilla, con el título Justicia como equidad (Madrid, Tecnos, 1986), donde fairness se vierte como equidad. Entre los estudiosos de Rawls, esta traducción ha sido la más aceptada, por lo que es común encontrarla en los estudios rawlsianos en español. El profesor García de la Sienra ha preferido el uso instalado por Miguel Ángel Rodilla, pero con ello se abre una disonancia con el texto canónico del propio Fondo de Cultura Económica. ¿No sería ya momento de que se hiciera una nueva traducción del libro original de Rawls para disolver los líos de traducción originados por el divisivo fairness?

Algo parecido puede decirse de otras elecciones terminológicas del profesor García de la Sienra: vierte las comprehensive doctrines aparecidas en Political Liberalism de 1993 como "doctrinas integrales", no obstante que tanto la traducción mexicana del Fondo de Cultura Económica de 1995 como la española de editorial Crítica de 1996 usaron la casi mecánica expresión “doctrinas comprehensivas”. Debo decir que prefiero la versión del profesor García de la Sienra, pero no dejo de ver que abre vías de confusión para estudiantes y estudiosos de la obra de Rawls en español. Más dudosas son sus traducciones de The Law of Peoples de Rawls (1996) como La ley de los pueblos (en lugar del clásico y filosóficamente más aceptable enunciado El derecho de gentes) o de 
The Right (que todo el rawlsianismo en español ha traducido como "lo correcto") como "El derecho". Finalmente, es de agradecer que nuestro traductor no ceda ante los graves errores conceptuales inducidos por la traducción del Fondo de Cultura Económica de Liberalismo político a cargo de Sergio R. Madero Báez, que lanza perlas como la de traducir la expresión rawlsiana "a standing point of view" (que califica a la concepción política de la justicia) como la absurda frase "un punto de vista libremente aceptado", cuando lo correcto sería "un punto de vista independiente”, o "autónomo”, como bien lo registra García de la Sienra.

Esta pequeña Torre de Babel que hemos construido los estudiosos de Rawls en castellano puede ser un buen pretexto para avanzar en el proyecto de una traducción y edición críticas de las obras de Rawls en nuestra lengua. El Fondo de Cultura Económica podría, sin duda, ser la instancia convocante.

Jesús Rodríguez Zepeda Universidad Autónoma Metropolitana-Iztapalapa 